\title{
HIV in the lung: guilty or not guilty?
}

In patients infected with HIV, respiratory disorders can occur in the absence of identifiable infection or neoplasms. As a cause of these non-specific pulmonary manifestations both Epstein Barr virus and HIV-I have been implicated. Numerous recent advances have been made in our understanding through morphological and functional studies on cell populations recovered in bronchoalveolar lavage (BAL) fluid from patients infected with HIV. Data now suggest a sequence starting with HIV infection of lung cells leading to a specific cytotoxic immune response; hence to local damage within the lung and deterioration in the alveolar capillary barrier. ${ }^{1}$ The sequence of events remains to an extent conjectural. This editorial reviews the evidence for HIV infection in the lung and its possible direct and indirect consequences.

\section{Do patients infected with HIV suffer from non-specific respiratory disorders?}

NON-SPECIFIC CLINICAL OR FUNCTIONAL ABNORMALITIES Patients infected with HIV but without identifiable lung infection or neoplasm can present with unexplained respiratory symptoms such as non-productive cough or dyspnoea on exertion or with interstitial opacities on $x$ ray film. ${ }^{2}$ Ognibene et al found a reduction in carbon monoxide transfer factor (TLCO) to less than $80 \%$ of predicted normal values in 12 of 24 AIDS patients who had no pulmonary symptoms, chest $x$ ray film abnormalities, or history of or prophylaxis against Pneumocystis carinii pneumonia. $^{3}$ Mitchell et al studied changes in TLCO prospectively in $474 \mathrm{HIV}$ seropositive patients, none of whom were intravenous drug users. As expected reduced values for TLCO were found in patients with pulmonary infections or neoplasms but reductions were also seen in patients with persistent generalised lymphadenopathy, AIDS related complex, non-pulmonary Kaposi's sarcoma, and non-pulmonary complications of AIDS excluding Kaposi's sarcoma. Mean TLCo values were lower in patients with more advanced HIV disease when compared with symptom free HIV seropositive patients. ${ }^{4}$ Rosso et al carried out technetium-99m-DTPA aerosol and gallium-67 scanning in 31 symptom free HIV seropositive patients and found accelerated DTPA clearance in 10 of 18 patients with normal chest radiographs and normal arterial blood gases. ${ }^{5}$ These studies show that some HIV seropositive patients without respiratory symptoms or abnormalities on chest radiography have reductions in TLCo or accelerated DTPA clearance, and suggest pathology at the alveolar level. ${ }^{4}$

\section{EVIDENCE FOR LYMPHOCYTIC ALVEOLITIS}

Several workers have analysed the cell composition of BAL fluid from HIV seropositive patients. Of 154 patients with lung infections or neoplasms Guillon et al found that $78 \%$ had an alveolar lymphocytosis (greater than $15 \%$ of total cell count; mean (SE) value $38(2) \%$ ). In a further 122 patients without lung infection or neoplasm $72 \%$ had lymphocytic alveolitis with mean (SD) values varying between $27(9) \%$ and 40 (7)\% depending on the state of HIV infection. Of 88 patients with alveolar lymphocytosis 27 had normal chest radiographs whereas 61 had either respiratory symptoms or diffuse interstitial opacities; thus lymphocytic alveolitis was seen not only in AIDS and AIDS related complex but also in earlier stages of $\mathrm{HIV}$ infection. ${ }^{2}$ Venet et al similarly found alveolar lymphocytosis in both AIDS patients and patients with AIDS related complex or persistent generalised lymphadenopathy. ${ }^{6}$ Further reports showed alveolar lymphocytosis during the later stages of HIV infection and, in particular, in AIDS patients. ${ }^{7-9}$ By contrast alveolar lymphocytosis was not found in earlier stages of HIV disease. Alveolar lymphocytosis was absent in patients with CDC group III, IVA, and $\mathrm{IV}_{\mathrm{C} 1}{ }^{7}$ in patients with CD4 counts greater than $400 / \mathrm{mm}^{3},{ }^{8}$ and in patients with neurological or constitutional disease. ${ }^{9}$ This difference in the percentage and absolute number of alveolar lymphocytes at early stages of HIV infection may be due to (a) differences among patient groups for risk factors for HIV infection-for example, in one study $63 \%$ of the patients were intravenous drug users ${ }^{7}$ whereas in another $7 \%$ were intravenous drug users, ${ }^{6}(b)$ differences in patient groups according to clinical presentation, BAL being performed either diagnostically for symptoms ${ }^{7}$ or as part of a prospective study in symptom free patients ${ }^{2} ;(c)$ interobserver error; problems may arise in distinguishing between large lymphocytes and small macrophages in BAL fluid. ${ }^{8}$ Phenotypic analysis in cases of lymphocytic alveolitis has shown an increase in both percentage and absolute number of T lymphocytes. Most of this is due to an increase in CD8 + lymphocytes in AIDS patients ${ }^{269}$ and those at earlier stages of HIV infection. ${ }^{26}$ Dual fluorescence FACS analysis has shown that the CD8+ lymphocyte populations correspond to two phenotypically and functionally distinct types: (1) cells positive for both CD8 and D44 markers identifying cytotoxic T lymphocytes $^{210}$; and (2) cells positive for CD8 and HNK1 (or CD57), which have suppressor activity. ${ }^{11}$ Although $\mathrm{CD} 8+$ and $\mathrm{D} 44+$ lymphocytes predominate during the early stages of HIV infection and CD8 + and HNK1 + cells at later stages, both are found in varying degrees at any stage of $\mathrm{HIV}$ infection. ${ }^{12}$

\section{EVIDENCE FOR INTERSTITIAL PNEUMONITIS}

Three types of interstitial pneumonitis have been reported in patients infected with HIV. ${ }^{13}$ Lymphocytic interstitial pneumonitis, which is particularly frequent in children and black adults, is associated with parotid enlargement, SICCA syndrome, and disseminated visceral lymphocytic infiltration. ${ }^{14-16}$ Studies on BAL fluid revealed lymphocytosis ${ }^{16}$ with $\mathrm{CD} 8+$ lymphocytes predominating. ${ }^{15-17}$ Biopsy studies confirm a generalised $\mathrm{CD} 8+$ lymphocytic infiltration particularly in the lungs. ${ }^{15}$ Whereas lymphocytic interstitial pneumonitis is a well characterised clinical entity this is not the case for non-specific pneumonitis ${ }^{18}$ where no aetiological agent has been identified but where other factors such as Kaposi's sarcoma, previous drug treatments, previous Pneumocystis carinii pneumonia, or intravenous drug use may be contributing to the pathology seen in the lungs. The third type, described by Ognibene et $\mathrm{al}^{3}$ as chronic non-specific interstitial pneumonitis, is of interest as 
these lesions were seen in 11 of 23 patients infected with HIV and with a circulating $\mathrm{CD} 4$ count of less than $200 / \mathrm{mm}^{3}$ in the absence of clinical pulmonary manifestations, suggesting a high frequency in their patients. Histological studies showed perivascular or peribronchial lymphoid interstitial infiltrates and aggregates similar to those seen in lymphocytic interstitial pneumonitis, suggesting a common mechanism. Therefore, lymphocytic alveolitis, non-specific interstitial pneumonitis, and lymphocytic interstitial pneumonitis may represent a spectrum of abnormalities involving the lymphoid system. ${ }^{13}$

\section{Is HIV present in the lung?}

It has been suggested that HIV may be responsible for these non-specific pulmonary disorders. Local immune responses mediated by cytotoxic lymphocytes (CTLs) have been found in other viral disease ${ }^{19}$ and can produce local lung damage ${ }^{20}$; there are also similarities between lymphocytic interstitial pneumonitis and chronic interstitial pneumonitis of sheep (Maedi), which is caused by a retrovirus. ${ }^{21}$. Also, lymphocytic interstitial pneumonitis with an increased number of CTLs has recently been described in association with HTLV1 infection, which is a type $\mathrm{C}$ retrovirus. ${ }^{22}$ The key issue, therefore, is whether $\mathrm{HIV}$ is present in the lung. Many investigators have shown the presence of HIV in the lung of patients with lymphocytic alveolitis, ${ }^{23}$ lymphocytic interstitial pneumonitis $^{13}{ }^{24-26}$ and AIDS, ${ }^{132-28}$ or at other stages of HIV infection. $^{8-1029}$ Initial studies detected HIV by standard techniques for demonstrating retroviral infection such as coculture and examination of supernatant fluids for reverse transcriptase activity or presence of P24 antigen by enzyme immunoassay. ${ }^{8427} 29$ Other techniques including Southern blot analysis of alveolar macrophage DNA, ${ }^{23}$ in situ hybridisation for HIV RNA in frozen lung sections, ${ }^{1326}$ and immunoenzyme analysis of alveolar macrophages using CD4 and CVK-A1 Mab specific for the P18 HIV protein have been used..$^{10}$ More recently the polymerase chain reaction technique has been used to detect HIV proviral DNA in BAL cells. ${ }^{28} 3031$ There is a striking contrast between the low rate of detection ( $9 \%-$ $18 \%$ ) of retroviral replication ${ }^{8427}$ and the high frequency with which HIV-I proviral DNA is detected in BAL cells $(58 \%-100 \%){ }^{283031}$ Polymerase chain reaction studies clearly show the frequent presence of cells containing HIV-I in the lungs of patients infected with HIV.

A number of further questions arise; firstly, which cells within the lung are infected? The relation between the expression of the CD4 receptor molecule and cell permissivity for HIV infection is now clearly established not only for lung lymphocytes but also for macrophages $^{10} 232632$ and fibroblasts. ${ }^{25}$ Moreover, in vivo infection of lymphocytes, ${ }^{29} 30$ macrophages, ${ }^{23} 2829$ and fibroblasts has been found in patients infected with HIV. Secondly, how many cells are infected? Chayt et al, using HIV RNA detection by in situ hybridisation, found low numbers in lung slices $(0 \%-0.002 \%)$ in the absence of lymphocytic interstitial pneumonitis, but this reflects only the replication of HIV within cells. ${ }^{26}$ Autran et al found a higher frequency (3-80\% of alveolar macrophages) by immunoenzyme analysis but this may only reflect adsorption of extracellular HIV proteins to the surface of alveolar macrophages. ${ }^{10}$ Thirdly, is HIV in a latent phase or actively replicating within infected cells? The contrast between low detection rates of virological markers for HIV replication and the frequent detection of HIV by polymerase chain reaction probably reflect the low transcription rate of HIV within lung cells but at this stage no firm conclusion can be drawn. Studies with comparable techniques including quantification of virus within infected cells are needed to resolve these issues.

\section{Is HIV responsible for lymphocytic alveolitis and} other forms of lymphoid pneumonitis?

The hypothesis that alveolar lymphocytes are probablyo recruited as an immune response to HIV infection of lung cells has recently been strengthened by two studies. Jeffrey et al found a correlation between the detection of $\frac{\text { sh }}{9}$ HIV-I by culture of unseparated cells and alveolar lymphocytosis of greater than $30 \% .{ }^{29}$ Similarly, Autran et a $\frac{\overline{\bar{c}}}{\mathrm{D}}$ found a correlation between the presence of provirus $\frac{\Phi}{\widetilde{\sigma}}$ HIV-I and the expression of P18 in BAL macrophages and the intensity of CD8 + lymphocytic alveolitis (per-s sonal communication 1992).

In an important early study Plata et al found that most CD8 + alveolar lymphocytes in BAL from patients $\vec{\sigma}^{\circ}$ with lymphocytic alveolitis or lymphocytic interstitial pneumonitis were CTLs with functional activity against ${ }^{x}$ autologous HIV-I infected alveolar macrophages. ${ }^{23}$ This ${ }^{\infty}$ spontaneous in vitro cytolytic activity was HLA restricted $\overrightarrow{\mathrm{N}}$ and at least partially specific for HIV envelope proteins. - Chenicer et al showed that patients infected with HIV-IE carry coexisting CTL subpopulations with differento specificities with ability to recognise epitopes of structural proteins of HIV such as external envelope and internalo core proteins as well as non-structural regulatory proteins on the surface of infected cells. ${ }^{33}$ These studies suggest that HIV specific CTLs represent a major componento within the lymphocytic alveolitis during the early stagesof HIV infection. These CTLs in some cases decreasee with time, however, ${ }^{11}$ and this is by contrast with the usual persistence of $\mathrm{CD} 8+$ lymphocytic alveolitis ino patients with AIDS. Jolly et al have recently found in these cases an increase in CD8 + lymphocytes coexpressing the HNK1 or CD57 antigen with suppressor activity? for both HIV specific CTLs and non-antigen specific killer cells such as NK cells and IL-2 driven LAK cells. ${ }^{1}{ }^{\overrightarrow{0}}$ The inhibitory activity of this cell population is mediated by a soluble non-antigen specific inhibitory factor that is distinct from $\mathrm{PGE}_{2}, \mathrm{TGF} \beta$, latent $\mathrm{TGF} \beta, \mathrm{TNF} \alpha$, and TNF $\beta .^{34}$ The CD8 + HNK1 + lymphocytes are therefore probably a major component of the lymphocytic alveolitis seen at late stages of HIV infection and act as down: regulators of the HIV specific CTL population Induction mechanisms for this cell population may be byô antigenic stimulation or cytokine secretion inducing the expression of HNK1 on CD8 + cells. Regardless of the actual induction mechanism the in vivo relevance of the inhibitory activity mediated by $\mathrm{CD} 8+\mathrm{HNK} 1+$ cells remains to be determined. They may well contribute ton the fall in HIV specific CTL activity found in AIDS patients but other mechanisms may also be responsible for example, a decrease in CTL or CTL precursors, $\omega$ impairment of CTL functions, in vivo selection of HIV mutants, destruction of CD4 + lymphocytes, or impair:은 ment of their function leading to decreased production of the cytokines required for the growth and function of antiviral CD8 + cells.

\section{Is HIV responsible for non-specific clinical and} functional respiratory disorders? Studies have suggested a relation between the degree of alveolar lymphocytosis and the existence of respiratory symptoms or chest radiographic abnormalities. ${ }^{2}$ Few studies have attempted to correlate the level of lung infection by HIV or the resulting CTL response with the existence and degree of respiratory disorders, however. 
Clarke et al looked for a relation between the presence of HIV-I and changes in the TLCO and other pulmonary function tests. They detected HIV-I proviral DNA in BAL cells in $58 \%$ of patients but in these patients values of DLCO were no lower than in patients without detectable HIV-I in BAL cells. ${ }^{31}$ By contrast Meignan et al investigated clearance of aerosolised technetium-99m DTPA in patients with cytotoxic or suppressive lymphocytic alveolitis. Increased DTPA clearance occurred only in patients with cytotoxic alveolitis, the increase correlating with the number and cytolytic activity of CD8+ $\mathrm{D} 44+$ lymphocytes. A further relation was found between the number of CTLs and $\mathrm{KCO}$ and $\mathrm{PaO}_{2}{ }^{1}$ The discrepancy between the results of these two studies may result from the fact that the investigators in the first study were attempting to correlate the epithelial permeability with the detection of HIV-I (perhaps at a latent stage) and in the second study, with the detection of an active immunological response. Even if the findings of Meignan et al are confirmed by other studies two questions remain. Firstly, what are the underlying mechanisms? Possibly HIV infected alveolar macrophages targeted by specific CTL release mediators such as IL-1, intracellular enzymes, free radicals, or TNF, some of which may result in alterations to the alveolocapillary barrier. Also HIV specific CTLs may have a direct effect against the alveolocapillary barrier after release of cytokines or proteolytic substances. Secondly, what is the evolution of changes in epithelial permeability with time? Spontaneous resolution of lymphocytic interstitial pneumonitis and normalisation of DTPA clearance measurements have been noted. ${ }^{135}$ This is not surprising when the decrease in numbers and decrease of activity of CTLs is considered with progression to AIDS. Patients in the late stages of HIV infection, however, not only maintain but also have increases in TLCO abnormalities. Factors other than CTL activity, such as impaired ability of the lungs to recover from inflammatory events after repeated infection, may be responsible at these stages of HIV disease. ${ }^{4}$

\section{Is HIV in the lung causing damage as a result of persistent cell activation and cytokine release?}

It has been clearly shown that alveolar macrophages, CD4 lymphocytes and fibroblasts can be infected by HIV both in vitro and in vivo but conditions promoting the replication of $\mathrm{HIV}$ in vivo in these cells remain unclear. ${ }^{2325282932}$ In vitro expression of HIV in infected cells is regulated by a number of events or factors including cell to cell interactions and certain cytokines-for example IL-1, IL-2, IL-6, TNF $\alpha$, and GM-CSF. ${ }^{36-38}$ These in vitro conditions may well exist at the local level within the lung at the site of immune and inflammatory responses during HIV infection or during opportunistic infections. In this situation it is possible that cytokine production would provide a local mechanism inducing tissue injury or leading to HIV replication. Production of certain cytokines (IL-1, IL-2, TNF $\alpha$, and GM-CSF) has been shown in the lung of HIV seropositive patients without opportunistic lung infection. ${ }^{39-44}$ Agostini et al found detectable levels of GM-CSF in BAL fluid from HIV infected patients. ${ }^{44}$ The levels of GM-CSF correlated with the absolute number of alveolar macrophages and lung neutrophils, which accords with the known effects of GM-CSF on granulocyte and macrophage growth and differentiation. Also, cell free supernatants obtained from unstimulated cultured alveolar macrophages from these patients (but not from purified alveolar lymphocytes) contained detectable amounts of
GM-CSF suggesting that these cells were the source of the in vivo production. Even more interesting was the finding of a 10-fold increase in GM-CSF after in vitro stimulation of macrophages from HIV seropositive patients compared with alveolar macrophages obtained from seronegative volunteers. Finally these macrophages were able to bind GM-CSF in vitro and to undergo proliferation suggesting possible activation through a paracrine pathway. Further studies have shown that alveolar macrophages from seropositive patients spontaneously produce greater amounts of $\mathrm{TNF} \alpha$ than macrophages from seronegative volunteers in the absence of opportunistic infection. ${ }^{41}{ }^{42}$ Israel-Biet et al showed that this spontaneous production was probably not due to a simple differentiation of monocytes into macrophages within the lung as the TNF $\alpha$ released by blood monocytes was similar to that from alveolar macrophages. ${ }^{41}$ This production of TNF $\alpha$ did not correlate with the clinical markers of HIV disease (AIDS related complex or AIDS) or with surrogate markers for disease progression such as a CD4 cell count of less than $400 / \mathrm{mm}^{3}$. By contrast, spontaneous TNF $\alpha$ release was partially related to the presence of lymphocytic alveolitis. Whether these lymphocytes stimulate TNF $\alpha$ release by macrophages as has been reported for cells obtained from blood ${ }^{45-47}$ remains to be determined. Perhaps the most interesting result of the current study was that alveolar macrophages infected with HIV had greater spontaneous production of TNF $\alpha$ than non-infected macrophages. This spontaneous production of cytokines by alveolar cells from symptom free seropositive patients suggests that immune responses developed against lung cells infected with HIV may be responsible for cellular activation and that HIV itself may modify the pattern of cytokine release in infected cells, as has been found in vitro. ${ }^{46-48}$ The precise role of these cytokines in the development of non-specific pulmonary disease or in the control of HIV replication within the lung remains to be determined. Pneumocystis carinii pneumonia results from severe $\mathrm{T}$ lymphocyte depletion in both patients and animal models. Despite this profound immunodeficiency Pneumocystis carinii pneumonia itself is commonly associated with an intense local inflammatory response, the extent of which is highly dependent on the presence of CD4 + lymphocytes and on the release of cytokines such as $\gamma$ IFN and TNF $\alpha .^{49-51}$ Several studies have measured the release of cytokines within the lung of AIDS patients with Pneumocystis carinii pneumonia ${ }^{3940414}$ and have shown that alveolar macrophages spontaneously produce high amounts of TNF ${ }^{39-42}$ Also, in one of these studies, it has been shown that this production is compartmentalised within the lung and that alveolar macrophages are refractory to further in vitro activation by $\gamma$ IFN. ${ }^{41}$ Despite the intensity of these inflammatory responses they seem to be ineffective against opportunistic infections, in particular Pneumocystis carinii pneumonia, in view of the high mortality without treatment. These studies suggest that cytokine release after stimulation of alveolar cells either by HIV infection itself or other pathogens may be more damaging than favourable. These mechanisms may be responsible for the non-specific pulmonary lesions found in seropositive patients and may also contribute to the severe alveolar damage in Pneumocystis carinii pneumonia. ${ }^{39} 41-44$ Also, these mechanisms may increase the load of HIV within the lung through the recruitment of $T$ lymphocytes and neutrophils and their activation either through cooperation with HIV infected macrophages $^{52}$ or in the environment of CD4 lymphocytes that are actively replicating HIV. ${ }^{36}$ Alternatively, alveolar lymphocytes or macrophages carrying latent HIV 
may actively replicate the virus through the up regulating effect leading to cytokine release. ${ }^{36}$ Cytokine release within the lung may also contribute to the formation of a growing pool of continuously activated alveolar macrophages, ${ }^{4143}$ which then spontaneously produce cytokines such as IL-1, TNF $\alpha$, and GM-CSF. ${ }^{39} 41-44$ These activated macrophages may then become refractory to later appropriate activation ${ }^{41-43}$ and thus expose the host not only to additional dissemination of HIV but also to the risk of opportunistic pulmonary infections.

In conclusion there is no doubt that HIV is present in the lungs of many HIV seropositive patients. On the basis of the foregoing discussion it may well be directly responsible for both opportunistic infection and neoplasms and also for some of the non-specific respiratory disorders seen in HIV infection. On the basis of the evidence discussed HIV is therefore found to be guilty; yet at the moment we lack the means to control its damaging activities within the lung. In the absence of effective antiretroviral treatment our future endeavour should be directed towards identifying and then controlling the involuntary and unwilling accomplices to the virus such as cytokines and activated cells that result in lung injury and predisposition to opportunistic infection.

We thank Dr DM Mitchell for reviewing this manuscript.

C M MAYAUD J CADRANEL Service de Pneumologie et de Reanimation Respiratoire, Hôpital Tenon, 4 rue de la Chine, Paris 75020, France

Reprint requests to: Professor C Mayaud

1 Meignan M, Guillon JM, Denis M, Joly P, Rosso J, Carette M-F, et al. Increased lung epithelial permeability in HIV-infected patients with isolated cytotoxic T-lymphocytes alveolitis. Am Rev Respir Dis 1990;141: 1241-8

2 Guillon JM, Autran B, Denis M, Fouret P, Plata F, Mayaud C, Akoun G. Human immunodeficiency virus-related lymphocytic alveolitis. Chest 1988;94:1264-70.

3 Ognibene F, Masur A, Rogers P, Travis W, Suffredini A, Feuerstein I, et al. Non specific interstitial pneumonitis without evidence of Pneumocystis carinii in asymptomatic patients infected with human immunodeficiency virus. Ann Intern Med 1988;109:874-9.

4 Mitchell DM, Fleming J, Pinching AJ, Harris JR, Moss FM, Veale D, Shaw RJ. Pulmonary function in human immunodeficiency virus infection. Am Rev Respir Dis 1992;146:745-51.

5 Rosso J, Guillon JM, Parrot A, Denis M, Akoun G, Mayaud C, et al. Technetium-99m-DTPA aerosol and gallium-67 scanning in pulmonary complications of human immunodeficiency virus infection. f Nucl Med 1992;33:81-7.

6 Venet A, Clavel F, Israel-Biet D, Rouzioux C, Dennewald G, Stern M, et al. Lung in acquired immune deficiency syndrome: infections and immunological status assessed by bronchoalveolar lavage. Bull Eur Physiopathol Respir 1985;21:535-43.

7 Palange P, Carlone S, Venditti M, Antony V, Angelici E, Forte S, et al. Alveolar cell population in HIV infected patients. Eur Respir $\mathcal{F} 1991$; 4:639-42.

8 Johnson JE, Anders GT, Hawkes CE, Lahatte L, Blanton HM. Bronchoalveolar lavage findings in patients seropositive for the human immunodeficiency virus. Chest 1990;97:1066-71.

9 Agostini C, Poletti V, Zambello R, Trentin L, Siviero F, Spiga L, et al. Phenotypical and functional analysis of bronchoalveolar lavage lymphocytes in patients with HIV infection. Am Rev Respir Dis 1988;138: 1609-15.

10 Autran B, Mayaud C, Raphael M, Plata F, Denis M, Bourguin A, et al. Evidence for a cytotoxic $T$ lymphocyte alveolitis in human immunodeficiency virus-infected patients. AIDS 1988;24:179-83.

11 Joly P, Guillon JM, Mayaud C, Plata F, Theodorou I, Denis M, et al. Cell-mediated suppression of HIV-specific cytotoxic T-lymphocytes. f Immunol 1989;143:2193-201

12 Quint L, Autran B, Guillon JM, Parrot A, Denis M, Debre P, et al. Alveolites lymphocytaires aux stades precoces de l'infection par le VIH: correlation avec les facteurs biologiques et le pronostic. Rev Mal Respir 1992;9:155-62.

13 Travis W, Fox C, Devaney K, Weiss L, O'Leary T, Ognibene F, et al. Lymphoid pneumonitis in 50 adults patients infected with the human mmunodeficiency virus. Hum Pathol 1992;23:529-41.

14 Itescu S, Brancato L, Buxbaum J, Gregersen P, Rizk C, Croxson S, et al. A diffuse infiltrative CD8 lymphocytosis syndrome in human immunodeficiency virus infection: a host immune response associated with HLA-DR5. Ann Intern Med 1990;112:3-10.

15 Guillon JM, Fouret P, Mayaud C, Picard F, Raphael M, Touboul JL, et al. Extensive T8-positive lymphocytic visceral infiltration in a homosexual man. Am $\mathcal{F}$ Med 1987;82:655-61.
16 Solal-Celigny P, Couderc J, Herman D, Herve P, Schaffar-Deshayes L, Brun-Vezinet $F$, et al. Lymphoid interstitial pneumonitis in acquired immunodeficiency syndrome-related complex. Am Rev Respir Dis 1985; 131:956-60.

17 Couderc L, Herve P, Solal-Celigny P, Herman D, D'Agay M, Morinet F, Pneumonie lymphoide interstitielle et polyadénopathies chez les sujets infectés per le virus LAV/HTLV III. Presse Med 1986;15:1127-30.

18 Suffredini AF, Ognibene FP, Lack E, Simmons J, Brenner M, Gill V, et al. Non-specific interstitial pneumonitis: A common cause of pulmonary disease in the acquired immunodeficiency syndrome. Ann Intern Med 1987;107:7-13.

19 McMichael A, Ting A, Zweerink H, Askonas B. HLA restriction of cellmediated lysis of influenza virus-infected human cells. Nature 1977; 270:524-7.

20 Cannon MJ, Openshaw P, Askonas B. Cytotoxic T cells clear virus but augment lung pathology in mice infected with respiratory syncytial virus. $\mathcal{F} \operatorname{Exp}$ Med 1988;168:1163-8.

21 Lairmore MD, Rosadio RM, DcMartini JC. Ovine lentivirus lymphoid interstitial pneumonia. Am f Pathol 1986;125:173-81.

22 Setoguchi Y, Takamashi S, Nukiwa T, Kira S. Detection of human T-cell lymphotropic virus type 1-related antibodies in patients with lymphocytic interstitial pneumonia. Am Rev Respir Dis 1991;144:1361-5.

23 Plata F, Autran B, Martins LP, Wain-Hobson J, Raphael M, Mayaud C, et al. AIDS-virus specific cytotoxic T-lymphocytes in lung disorders. Nature 1987;328:348-51.

24 Dean NC, Golden JA, Evans LA, Warnock ML, Addison JE, Hopewell PC, Levy JA. Human immunodeficiency virus recovery from bronchoalveolar lavage fluid in patients with AIDS. Chest 1988;93:1176-9.

25 Plata F, Garcia-Pons F, Ryter A, Lebargy F, Goodenow M, Quan Dat M, et al. HIV infection of lung fibroblasts and macrophages in humans. AIDS Res Human Retroviruses 1990;6:979-86.

26 Chayt KS, Harper ME, Marselle LM, Lewin EB, Rose RM, Oleske JM, et al. Detection of HTLV III RNA in lungs of patients with AIDS and pulmonary involvement. $\mathcal{F A M A} 1986 ; 256: 2356-59$.

27 Linnemann C, Baughman R, Frame P, Floyd R. Recovery of human immunodeficiency virus and detection of P24 antigen in bronchoalveolar lavage fluid from adult patients with AIDS. Chest 1989;96:64-7.

28 Rose R, Krivine A, Pinkston P, Gillis J, Huang A, Hammer S. Frequent identification of HIV-1 DNA in bronchoalveolar lavage cells obtained from individuals with the acquired immunodeficiency syndrome. $\mathrm{Am}$ Rev Respir Dis 1991;143:850-4.

29 Jeffrey A, Israel-Biet D, Andrieu JM, Even P, Venet A. HIV isolation from pulmonary cells derived from bronchoalveolar lavage. Clin Exp Immunol 1991;85:488-92.

30 Clarke J, Krishnan V, Bennett J, Mitchell M, Jeffries D. Detection of HIV-1 in human lung macrophages using the polymerase chain reaction. AIDS 1990;4:1133-6.

31 Clarke J, Fleming J, Donegan K, Moss F, Nieman R, Williamson J, Mitchell D, et al. Effect of HIV-1 and cytomegalovirus in bronchoalveolar cells on the transfer factor for lung carbon monoxide in AIDS patients. AIDS 1991;5:1333-8.

32 Salahuddin SZ, Rose RM, Groopman JE, Markham PD, Gallo RC. Human T-lymphotropic virus type III infection of human alveolar macrophages. Blood 1986;68:281-4.

33 Chenciner N, Michel F, Dadaglio G, Langlade-Demoyen G, Hoffenbach A, Leroux A, et al. Multiple subsets of HIV-specific cytotoxic Tlymphocytes in humans and in mice. Eur f Immunol 1989;19:1537-44.

34 Sadat-Sowti B, Debre P, Idziorek T, Guillon JM, Hadida F, Oksenhendler E, et al. A lectin-binding soluble factor released by CD8 + CD57 lymphocytes from AIDS patients inhibit $\mathrm{T}$ cells cytotoxicity. Eur 7 Immunol 1991;21:737-41.

35 Grieco M, Chinoy-Achary AP. Lymphocytic interstitial pneumonia associated with the acquired immune deficiency syndrome. Am Rev Respir Dis 1985;131:952-5.

36 Rosenberg ZF, Fauci AS. Immunopathogenic mechanisms of HIV infection: cytokine induction of HIV expression. Immunology Today 1990;11: 176-80.

37 Israel N, Hazan U, Alcami J, Munier A, Arenzana-Seisdedos F, Bachelerie $\mathrm{F}$, et al. Tumor necrosis factor stimulates transcription of HIV-1 in human T lymphocytes, independently and synergistically with mitogens. F Immunol 1989;143:3956-60.

38 Poli G, Bressler P, Kinter A, Duh E, Timmer WC, Rabson A, et al. $\mathrm{N}$ Interleukin 6 induces human immunodeficiency virus expression in $\sigma$ infected monocytic cells alone and in synergy with tumor necrosis factor $\alpha$ by transcriptional and post-transcriptional mechanisms. $\mathcal{f}$ Exp Med 1990;172:151-6.

39 Krishnan VL, Meager A, Mitchell DM, Pinching AJ. Alveolar macrophages in AIDS patients: increased spontaneous tumor necrosis factor-alpha production in Pneumocystis carinii pneumonia. Clin Exp Immunol 1990;80:156-60.

40 Cox RA, Anders GT, Cappelli PJ, Johnson JE, Blanton HM, Seaworth BJ, Treasure RL. Production of tumor necrosis factor-alpha and interleukin-1 by alveolar macrophages from HIV-1-infected persons. AIDS Res Hum Retroviruses 1990;6:431-7.

41 Israel-Biet D, Cadranel J, Beldjord K, Andrieu JM, Jeffrey A, Even P. Tumor necrosis factor production in HIV seropositive subjects. Relationship with lung opportunistic infections and HIV expression in alveolar macrophages. F Immunol 1991;147:490-4.

42 Agostini C, Zambello R, Trentin L, Garbisa S, Di Celle PF, Bulian P, et $<$ al. Alveolar macrophages from patients with AIDS and AIDS-related complex constitutively synthesize and release tumor necrosis factor $\alpha$. Am Rev Respir Dis 1991;144:195-201.

43 Agostini C, Trentin L, Zambello R, Bulian P, Caenazzo C, Cipriani A, 厄ॄ et al. Release of granulocyte-macrophage colony-stimulating factor by alveolar macrophages in the lung of HIV-1-infected patients. A mechanism accounting for macrophage and neutrophil accumulation. nism accounting for manol 1992;149:3379-85.

44 Biglino A, Forno B, Pollono AM, Ghio P, Albera P. Alveolar immune 
mediators in HIV-related pneumonia; different role of IL2 and IL1 in inducing lung damage. Chest 1993;103:439-44.

45 Schrier RD, McCutchan JA, Venable JC, Nelson JA, Wiley CA. T-cellinduced expression of human immunodeficiency virus in macrophages. f Virol 1990;64:3280-5.

46 Merrill JE, Koyanagi Y, Chen ISY. Interleukin-1 and tumor necrosis factor $\alpha$ can be induced from mononuclear phagocytes by human immunodeficiency virus type 1 binding to the CD4 receptor. $f$ Virol 1989;63:4404-8.

47 Molina J-M, Scadden DT, Byrn R, Dinarello CA, Groopman JE. Production of tumor necrosis factor $\alpha$ and interleukin $1 \beta$ by monocytic cells infected with human immunodeficiency virus. $\mathcal{f}$ Clin Invest 1989; 84:733-8.
48 Clouse KA, Cosentino LM, Weih KA, Pyle SW, Robinns PB, Hochstein $\mathrm{HD}$, et al. The HIV-1 gp120 envelope protein has the intrinsic capacity to stimulate monokine secretion. F Immunol 1991;147:2892-6.

49 Furuta T, Ueda K, Fujiwara K, Yamanouchi K. Cellular and humoral immune responses of mice subclinically infected with Pneumocystis carinii. Infect Immunol 1985;47:544-8.

50 Harman AG, Stankiewicz M. Requirement for CD4 + cells in resistance to Pneumocystis carinii pneumonia in mice. 7 Exp Med 1990;172:937-45.

51 Pesanti EL. Interaction of cytokines and alveolar cells with Pneumocystis carinii in vitro. $\mathcal{F}$ Infect Dis 1991;163:611-6.

52 Mann DL, Gartner S, Le Sane F, Buchow H, Popovic M. HIV-1 transmission and function of virus-infected monocytes/macrophages. f Immunol 1990;144:2152-8.

\section{Adventitia}

\section{Woods and trees}

"Are you the obsessional type?" asked the interviewer. "Do you lie awake worrying about upside down quotation marks?" "Oh no!" I laughed. The hoped for answer to this half serious question, however, was "yes"; but happily I got the job. The interviewer was Dr Joan Faulkner, wife of Sir Richard Doll, and the job was in the publications section of the Medical Research Council's headquarters. Thirty three years later I can say that anyone who is deeply obsessional would find much to lose sleep over and had better not do an editorial job: perfection may be unrealistic, and anyway it is often better to see the wood than every branch of every tree.

At the MRC "the wood" was for many years absorbing and often immensely exciting. At Oxford I had read Classics and philosophy and then I had briefly taught Latin and Greek; so to learn something of molecular biology, cytogenetics, and radiobiology, for example, seemed a great privilege-especially in the 1960s, when these were key growing points of research. A labour intensive but seductive part of the work was to make the scientific articles in the council's annual report to parliament more reader friendly for MPs and other "intelligent laymen"; but probably few laymen read these articles, at least those fascinating and intricate ones (on, for example, bacterial sexuality) on which I lavished such loving care. So eventually they gave way to shorter pieces on recent developments.

In $1977 \mathrm{I}$ joined the $B M \mathcal{H}$, where I wrote articles and was correspondence editor as well as subediting and sometimes rewriting papers. The editor, Stephen Lock, who taught me so much, coined the word "glogging" (verb "to glog") for the radical editing he wanted me to do. I loved my work with the $B M \mathcal{F}$ but in 1982, after getting married, I wanted a part time job and was lucky to be able to move to Thorax. Here I enjoyed working with successive editors and their assistants, the many authors with whom I had contact, and my friends at the printers, Eyre and Spottiswoode. Deadlines imparted a certain drama to the work and I became a familiar but finally unwelcome figure at the late post sorting office to which, if necessary, I walked or jogged or, as a last resort, drove.

The BMF style book, which Thorax largely follows, provided a court of appeal-especially useful for editorial changes made mainly for consistency, like putting a comma before "and" ("red, white, and blue"), to take a small example. But all through my career it irritated me if someone said patronisingly, "You look after the grammar and the commas and things, don't you?"-partly because I did much more than this, but also because these may be a route to both clarity and logic, and even to a critical analysis of the writing, providing tools for sorting out muddles. The use of the subjunctive, as in "If I were editor," illustrates usage that is rooted in logic but also in convention, its use being much more sparing in English than in some other languages. More interesting and important are the cases where logic holds a less disputable sway, as in the misuse of commas to separate the inseparable, as Fowler puts itcommon in complex sentences, especially between subject and predicate: "The pressure you experience by wanting to reach a certain goal .... in a limited time, is called time pressure." Similarly, the presence and absence of commas with descriptive and defining words and clauses are not a matter of taste, for they depend on what job the word(s) or clause is doing in the sentence: compare "The editor, who deals with editorials" with "The editor who deals with editorials." Of course I could go on and on, with examples of increasing complexity; but the Editor wouldn't like it.

Language, however, is dynamic and flexibility must have a place, though I took exception to the opening of a Sunday Times article of long ago: it claimed that a particular phrase had become correct thanks to British Rail.

DAPHNE GLOAG

(Technical Editor of Thorax from 1982 to 1993)

This column is now open to allcomers for suitable contributions (maximum 600 words). We would like to keep this column running. SGS 